\title{
Editorial
}

\section{Improvisation's Ebb and Flow}

\section{Frederique Arroyas}

The idea that improvisation is created ex nihilo is one that practitioners and theorists continue to push against. Spontaneity relies on a discipline of readiness and an awareness of one's environment. Hard work and commitment underlie the seemingly impulsive spontaneity of a performer's gestures. Consider improvisation as ebb and flow between internalized skills and extemporaneous utterances, a continuous probing of acquired knowledge to pursue an adapted, and adaptable, form of expression. The articles in this issue of CSI-ECI investigate this alternate backward and forward movement on a number of planes-historical, cultural, and individual.

In "Living With the I-Word: Improvisation and its Alternates," Robert Labaree's analysis is purposefully anchored in repertoires that do not rely on the jazz-related conventions of improvisation: the music of Chopin, the songs of medieval troubadours, folk music of the Balkans and the British Isles, and Turkish classical music. Studying improvisation in these repertoires allows him to isolate specific qualities of improvisation that the ubiquity of the "Iword" has rendered too foggy or diffuse. Alternate notions such as musicianship, variability, and performer control, studied in these specific contexts, demonstrate the different meanings that improvisation takes on across histories and cultures.

Samuel Curkpatrick investigates the collaboration between Aboriginal Australian musicians and the Australian Art Orchestra in a project known as "Crossing Roper Bar." In this cross-cultural encounter, the ancestral tradition of manikay songs fuses with new contexts and modes of expression, attesting to the vitality of a tradition engaged with the present. The emergent dialogue can be considered, according to Curkpatrick, as "a type of understanding that resists assimilation and cultural subordination." In honour of this dialogue, we are happy to feature, on this issue's splash page, a photograph and audio sample from a 2010 concert in the remote Aboriginal community of Ngukurr.

Another example of how the present may come to resonate with the past is Jeremy Strachan's "Reading Ascension: Improvisation, Text, and Analysis." His analysis of contemporary performances of John Coltrane's epic work includes interviews with musicians that draw out the "interpretative variability of performers as listeners." Improvising within the structure of Ascension, some ensemble members connected with the work's historical, symbolic, and political legacy whereas others responded to different stimuli. Strachan thus foregrounds the dialectical nature of improvisation. By way of literary theory, he stresses "music's textuality, as a way of tracing networks between composers and performers as they stretch across expanses of time and space."

Focussing on moments of failure that occur during improvised encounters, Stephanie Hill's "'An Invitation for Disaster'-Embracing the 'Double Failure' of Improvisation" considers the representational and relational aesthetics of these moments. Hill examines her own responses to accidents and mistakes during a performance she gave as part of a variety show. Her premise is that by not only accepting and working with failed events, but also by actively courting failure and being inspired by what such courtship can produce, performers can enhance their praxis and generate new artistic products.

Finally, we are pleased to include in this issue's 'Notes and Opinions' section a keynote address given at the 2012 Guelph Jazz Festival Colloquium by Jesse Stewart, an award-winning percussionist, composer, improviser and a professor of music at Carleton University, in which he reflects on his experiences as both a student and teacher of musical improvisation. From his jaunts as a teenager to downtown Toronto jazz concerts to the more formal educational setting of the university classroom, Stewart considers the ways in which an aesthetic of improvisation can act as a teaching strategy, generating a model for interactions between teacher and student. Against this backdrop of personal experiences, Stewart draws out how pedagogy and improvisation engage with issues of social justice and social responsibility.

As CSI-ECl enters its $10^{\text {th }}$ year of existence and in recognition of the forces that ensure continuity between the past and the future, we gratefully acknowledge the generous support of the University of Guelph and the Social Sciences and Humanities Research Council of Canada through its Aid to Scholarly Journals grant. Heartfelt thanks are due to the dedicated CSI/ECI team: fellow editors Daniel Fischlin and Ajay Heble; reviews editor Rob Wallace; Managing Editor Michelle Peek; Mark Kaethler, and Greg Fenton for their copyediting/proofreading expertise; and the invaluable support of Wayne Johnston, head of Research Enterprise and Scholarly Communication at the University of Guelph library. Most importantly, we wish to thank the authors, reviewers, and readers who constitute a broad and diverse base of knowledge users and contributors and who have helped to sustain and to advance the intellectual direction of the journal. 